\title{
Preference Measures of Rectangle Ratio on MBTI Personality Types
}

\author{
Ching-Yi Wang \\ Department of Industrial Design, Tatung University, Taipei City, Taiwan \\ Email: catincar@gmail.com
}

Received 16 March 2015; accepted 4 July 2015; published 7 July 2015

Copyright (C) 2015 by author and Scientific Research Publishing Inc.

This work is licensed under the Creative Commons Attribution International License (CC BY). http://creativecommons.org/licenses/by/4.0/

(c) (i) Open Access

\begin{abstract}
Whether the golden ratio is the favorite ratio for people is a controversial research issue until now. The purpose of this study is to investigate whether oriental people in Taiwan have the preference to the western culture originated golden ratio and to find out how the personality affects ratio preference by using the MBTI (Myers-Briggs Type Indicator) test to classify people into different personality types. First, 120 participants classified into 16 identified personality types by the MBTI test were screened out from 195 participants recruited in this study. After that, they were asked to estimate the preference to 15 horizontal and 15 vertical rectangles with varied ratios, respectively. The results of the study were summarized as follows: 1) The most popular personality types of the participants were ISTJ and ISFJ types, while ENTJ and ESTP types were much less popular; 2) The tendency of preference to varied ratios could be divided into three classes: people tended to like the ratio of a square, the preference to golden ratio was fair, and when the ratio increased to exceed the golden ratio would be gradually disliked; 3 ) The personality would affect the preference to golden ratio. The $\mathrm{V6}, \mathrm{H7}$ and $\mathrm{H} 8$ ratios were liked by people with different types of personality, I type and $T$ type people preferred $V 6$, people of $S$ type and $J$ type preferred $\mathrm{H} 7$ and people of $F$ type and J type preferred H8; 4) Women with non-designer background liked golden ratio, but men disliked it. Most designers preferred golden ratio. This result could be used as guidelines for product design and market position setting.
\end{abstract}

\section{Keywords}

Golden Ratio, MBTI, Preference Measures

\section{Introduction}

In the history of humans, the concept of "ratio" has been widely applied in architecture, furniture, crafts arts, and paintings. There are some ratios which have been regarded as the ideal ones for achieving aesthetic quality in 
design. Among them, the most significant one is the "golden ratio". The golden ratio of $1 / 1.618 \ldots$ has been treated as the "Divine Proportion" by the famous mathematician Pacioli (Mario, 2003). But do people really prefer this ratio? There have been experiments to investigate this question but without consistent results. Some studies proved the existence of preference to golden ratio (Benjafield, 1976, 2001; Benjafield \& Adams-Webber, 2001; Fechner, 1876). On the contrary, some studies denied this preference (Godkewitsch, 1974; McManus, 1980; Schiffman \& Bobka, 1978). The reasons for the consistent results may be due to the different experiment methods (for example, the rectangle is placed vertically or horizontally), and the different methods of assessment (assessment by ordering or assessment by comparing to standard). But some demographic or characteristic attributes of participants, such as age, gender, cultural background and personality, may affect the preference trend to golden ratio. For example, Thompson (1946) found the different preference trends to ratio among different age groups. On the other hand, Nienstedt \& Ross (1951) discovered that participants from 61 to 91 years old more preferred to the ratio of a square.

Personality may be another critical factor to affect aesthetic evaluation. For example, Lin \& Chuang (2003) adopted the Lai Personality Scale to investigate the influence of participants' personality on their color preferences. It showed that people with different personality types did have different preference trends on color. Huang discovered that there was association between preference on color and personality for college students with art background (Huang, 2008). Therefore, Personality may be a significant factor to affect the preference to golden ratio. However, there is no research addressed to this issue so far.

The purpose of the study aims to survey how the different types of personality affect the degree of preference to rectangle ratios. Cultural background of participants may also be an important factor which will affect the preference to golden ratio. Since the origin of golden ratio is from western culture, whether oriental people have the same preference to golden ratio is doubtable. Previous studies on preference to golden ratio were basically conducted to western people. By comparing the result of this study on oriental participants with those of previous studies, different trends may be revealed due to cultural background. In addition, this study will compare the difference between male and female participant on the preference to golden ratio.

There are many scales to classify people into different personality types. Among them, the Myers-Briggs Type Indicator (MBTI), which will be adopted in this study, is the well-known and widely applied character test after 50 years of development (Pittenger, 1993). The test classifies people into 16 different personality types according to their answers to a set of 2-polar questions in four distinctive aspects. The four aspects and the eight dimensions of genetic predisposition are: 1) E (Extraversion) or I (Introvert) type psychological inclination; 2) Understanding the external world through S (Sensing) or N (iNtuition) type; 3) Relying on T (Thinking) or F (Feeling) type for decision making; 4) Lifestyle and dealing with people through J (Judging) or P (Perceiving) type attitudes. These letters of combination will form the 16 different personality types, as shown in Figure 1 (Kroeger \& Thuesen, 1988).

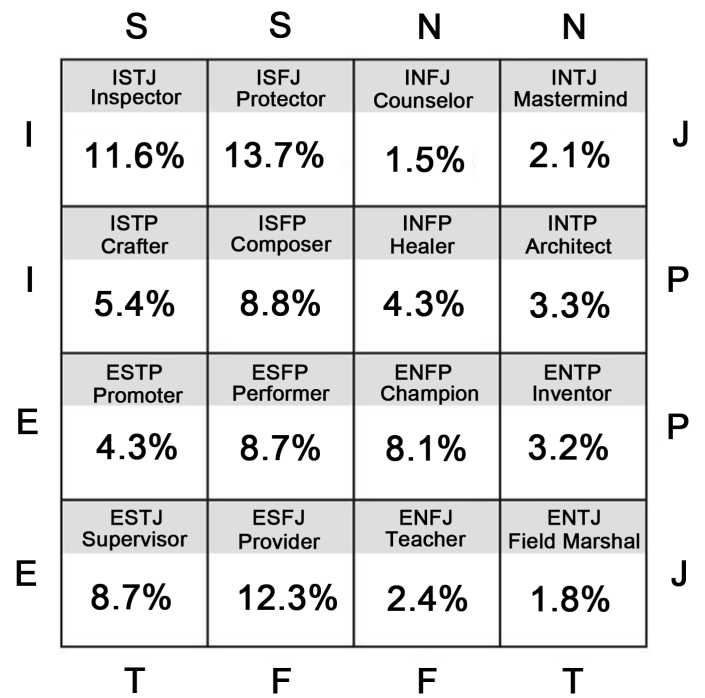

Figure 1. The sixteen Myers-Briggs personality types. 


\section{Material and Methods}

\subsection{Participants}

The study conducted personality survey to 195 participants ( 99 males and 96 females). Among them, 75 participants (41 males and 34 females) are with mixed personality, the participants show two or more personality types. The remaining 120 participants (58 were males and 72 females) with single-type personality were used as participants for further survey on preference to rectangle with different ratios. The age of these participants ranges from 20 to 34 years old with an average age of 25.6 years ( $\mathrm{SD}=3.0$ years). With respect to professional background, there are 48 participants with design training background and 72 participants without design training background.

\subsection{Procedure}

\subsubsection{MBTI Personality Testing System}

This study utilized Visual Basic 6.0 programming to put the content of MBTI personality test questions into the MBTI Experimental Vehicle System (Figure 2), which contained questionnaires for basic information of participants and for personality test with a total of 70 questions. Each personality test question contains two choices "a" and "b". Among them, the EI personality test contains 10 questions, while the SM, TF and JP tests contain 20 questions, respectively. The questions of test are referred from the site:

http://tracymanford.typepad.com/test.pdf. Upon starting the system, the participants are asked to fill in their personal information, including sex, age, professional background and way to contact with, before entering to the phase of personality test.

\subsubsection{Measurement on Preferred Rectangle Ratios}

The preference experiment of rectangle ratios then was subsequently followed after the completion of personality test. Adopting from the experiment conducted by (Godkewitsch, 1974), there are 15 ratios of rectangle (side 1/side 2) to be tested, including 1, 1.07, 1.15, 1.23, 1.32, 1.41, 1.51, 1.62, 1.74, 1.86, 1.99, 2.14, 2.30, 2.46 and 2.64. The tested samples consisted of horizontal and vertical sets of samples (the length of the horizontal rectangle, marked as $\mathrm{H}$, is equal to or larger than its height; the vertical rectangle, marked as $\mathrm{V}$, is the reverse of $\mathrm{H}$.) Each set contains 15 rectangles, with a total number of 30 rectangles to be tested, as shown in Figure 3 . The ratio of rectangle $\mathrm{H} 8$ and $\mathrm{V} 8$ is golden ratio. The actual size of tested samples measured in the screen is $2 \mathrm{~cm}$ for the ratio 1, i.e. with the size of $2 \mathrm{~cm} \times 2 \mathrm{~cm}$ for the squares (H1 and V1); with size of $2 \mathrm{~cm} \times 5.28 \mathrm{~cm}$ for the 1:2.64 rectangles (H15 and V15), and so on. All tested samples were presented to the each participant one by one in random order. Participants were ask to report their preference to each rectangle by using an assessment scale from 1 to 5 (with 1 being the least favorite, 5 being the most favorite.) Upon completion of the experiment, the "testing questionnaire.txt" file will be automatically generated from the MBTI Experimental Vehicle System for further analysis.

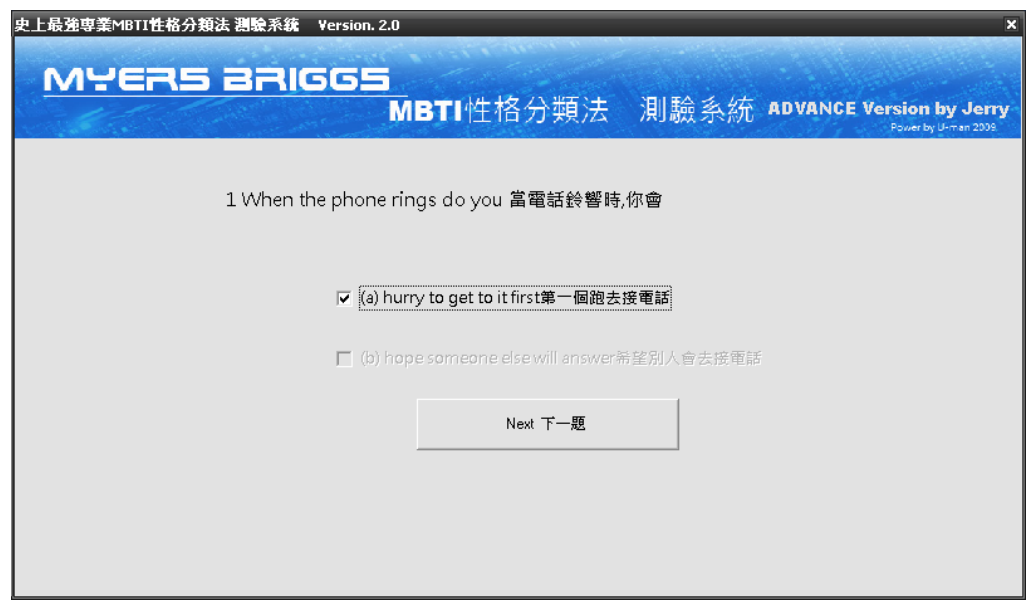

Figure 2. MBTI personality test vehicle system. 


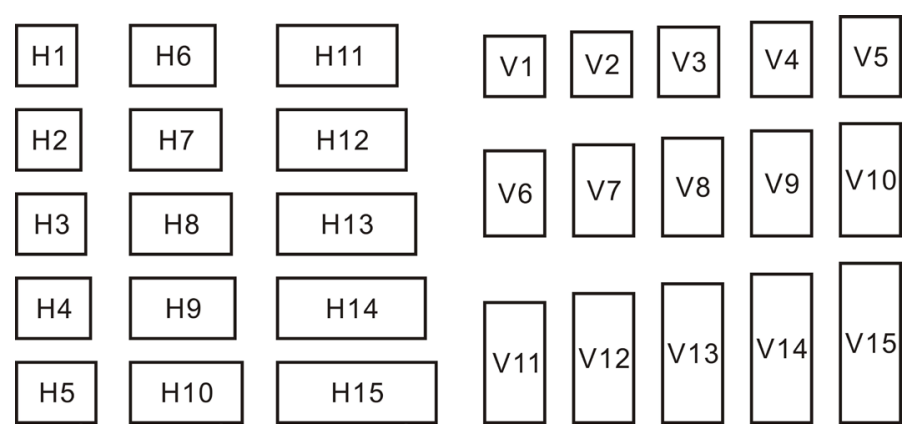

Figure 3. Tested samples of rectangles with different ratios.

\section{Result and Discussion}

This study computed the score of each participant according to his response to the MBTI test first, and then classified him into one of the 16 personality types. The result is shown Figure 4 . In this figure, the percentage in the middle is the classified result of this study, whereas the percentage on the lower right corner represents the result (Dolphin, 2009). The personality types which account for the majority ratio are the following in order: ISFJ protector type, ISTJ inspector type, ESFJ provider type, and INFP architect type; whereas the personality distributed with the least ratio are the following in order: INTJ mastermind type, ESTP promoter type and ENTJ field marshal type.

\subsection{The Result of Measurement on Preferred Rectangle Ratios}

The averaged preferred scores to rectangles were calculated and plotted as curves in Figure 5. The general preference to varied ratios of $\mathrm{H}$ rectangles (shown as the "all" curve in Figure 5(a)) could be divided into two trends: 1) The ratios of H1 - H2 are preferred (mean = 3.7); 2) The preference to ratios of H3 - H15 is about average (mean $=3$ ). That of V rectangles could be divided into three trends ("all" curve in Figure 5(b)): 1) The ratios of V1 - V2 preferred (mean = 3.6); 2) The ratios of V3 - V9 are neither liked nor disliked (mean = 3.1); 3) The ratios of V10 - V15 are disliked (mean $=2.7$ ). These differences have been verified to be significant by the Chi square test. It is discovered that people preferred rectangles with ratio closed to a square, the preference decreases with the increase of ratios. Further statistical test revealed that, the preference scores of the rectangles $\mathrm{V} 6, \mathrm{H} 7$, and $\mathrm{H} 8$ (with ratios closed to golden ratio) were significantly larger than 3 , for almost all types of people. Thus, golden ratio is slightly preferred by people in Taiwan, though it is less preferred than the ratio of $1: 1$.

\subsection{Different of Preference for Different Gender and Backgrounds}

Upon conducting the Independent Samples t-Test, we discovered that the male and female participants with non-designer background will display significant difference of preference to golden rectangle $(\mathrm{t}=-2.7, p=$ 0.009 ). Males with non-designer background dislike H8 (Mean $=2.8, \mathrm{SD}=0.8)$, while females like H8 (Mean $=$ $3.2, \mathrm{SD}=0.8$.) On the contrary, the participants with designer background do not reveal any significant difference caused by the factor of gender.

\subsection{Difference of Preference for Different Personalities}

The overall result shows significant different on $\mathrm{H} 8(\mathrm{~F}=2.0, p<0.05)$, with the degree of preference falling on average. The following conducts Duncan's post comparative analysis with emphasis on the $\mathrm{N}$ type, $\mathrm{F}$ type and $\mathrm{J}$ type of people with degree of preference for $\mathrm{H} 8$ reaching significance, in order to attain the difference of preference among all personalities. Applying Duncan's test and we discovered that (Table 1), there is no significant clustering for $\mathrm{N}$ type and $\mathrm{J}$ type; while $\mathrm{F}$ type displays significant clustering. In particular, ESFP performer type and ENFJ teacher type personalities like H8 the most, however ENFP mastermind type least likes H8. Each type is further clustered by genders and applied with Independent Samples T-Test to find out only N type shows significant difference in gender $(\mathrm{t}=-3, p=0.005)$. The $\mathrm{N}$ type man does not like $\mathrm{H} 8$ (Mean $=2.6, \mathrm{SD}=0.9)$, while the $\mathrm{N}$ type female like $\mathrm{H} 8$ (Mean $=3.4, \mathrm{SD}=0.1$ ), with the two displayed a contradictory degree of preference. 


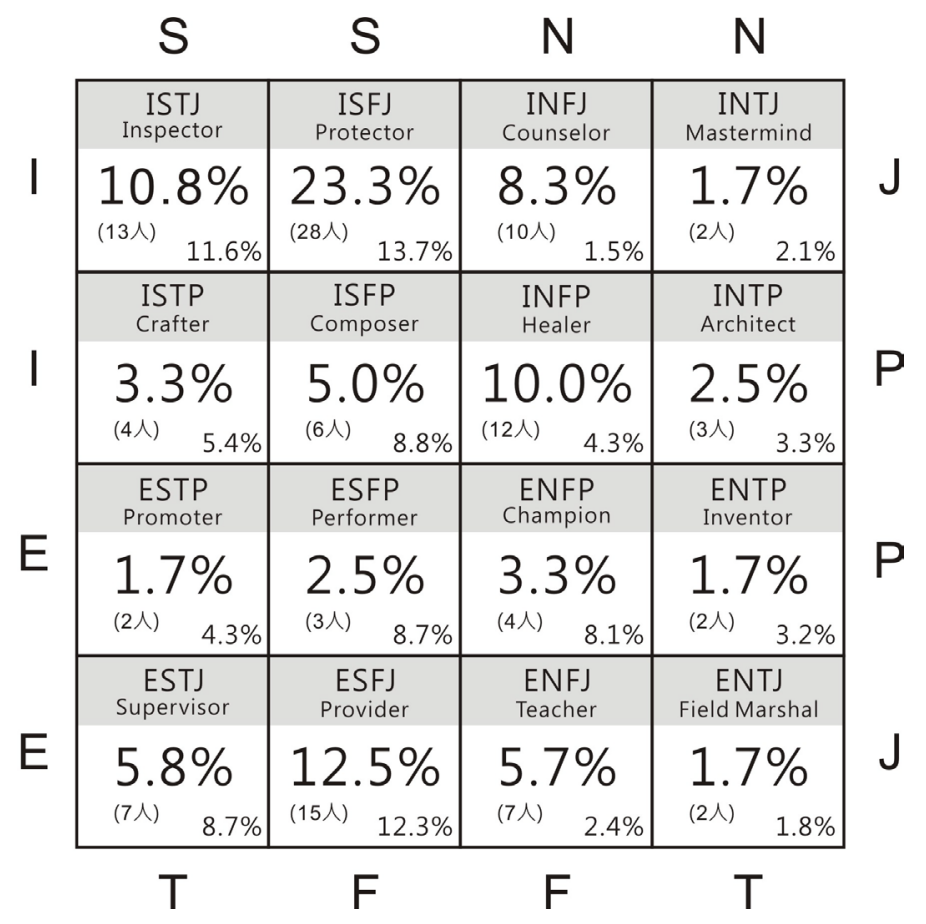

Figure 4. Percentage and statistical result of 16 personality types (tested number of participants for this study was 120 people).

Table 1. The result of measurement on $\mathrm{H} 8$ for $\mathrm{N}, \mathrm{F}$ and $\mathrm{J}$ type.

\begin{tabular}{|c|c|c|c|c|c|}
\hline & $\mathrm{N}$ & iNtuition & Feeling & Judging & All \\
\hline ESFP (Champion) & 3 & - & $\mathrm{a}$ & - & $3.7(0.6) \mathrm{a}$ \\
\hline ENFJ (Architect) & 7 & a & $\mathrm{a}$ & $\mathrm{a}$ & $3.6(0.8) \mathrm{a}$ \\
\hline ISTJ (Inspector) & 13 & - & - & $\mathrm{a}$ & $3.5(0.7) \mathrm{a}$ \\
\hline INTJ (Supervisor) & 2 & a & - & $\mathrm{a}$ & $3.5(0.7) \mathrm{a}$ \\
\hline ENTP (Inventor) & 2 & a & - & - & $3.5(0.7) \mathrm{a}$ \\
\hline ENTJ (Field Marshal) & 2 & $\mathrm{a}$ & - & $\mathrm{a}$ & $3.5(0.7) \mathrm{a}$ \\
\hline INTP (Composer) & 3 & $\mathrm{a}$ & - & - & $3.3(0.6) \mathrm{a}$ \\
\hline ESFJ (Teacher) & 15 & - & $\mathrm{a}, \mathrm{b}$ & $\mathrm{a}$ & $3.2(0.9) \mathrm{a}, \mathrm{b}$ \\
\hline ISFP (Protector) & 6 & - & $\mathrm{a}, \mathrm{b}$ & - & $3.2(0.8) \mathrm{a}, \mathrm{b}$ \\
\hline ESTP (Counselor) & 2 & - & - & - & $3.0(1.4) \mathrm{a}, \mathrm{b}$ \\
\hline INFP (Provider) & 12 & a & $\mathrm{a}, \mathrm{b}$ & - & $3.0(1.0) \mathrm{a}, \mathrm{b}$ \\
\hline INFJ (Performer) & 10 & $\mathrm{a}$ & $a, b$ & $\mathrm{a}$ & $3.0(0.8) \mathrm{a}, \mathrm{b}$ \\
\hline ISTP (Crafter) & 4 & - & - & - & $2.8(0.5) \mathrm{a}, \mathrm{b}$ \\
\hline ESTJ (Healer) & 7 & - & - & $\mathrm{a}$ & $2.7(1.0) \mathrm{a}, \mathrm{b}$ \\
\hline ISFJ (Promoter) & 28 & - & $b, c$ & $\mathrm{a}$ & $2.6(0.6) \mathrm{a}, \mathrm{b}$ \\
\hline ENFP (Mastermind) & 4 & $\mathrm{a}$ & $\mathrm{c}$ & - & $2.0(0.0) \mathrm{b}$ \\
\hline Mean (S.D.) & 120 & $3.1(0.9)$ & $3.0(0.8)$ & $3.0(0.8)$ & $3.0(0.8)$ \\
\hline
\end{tabular}

a, b: Duncan. 

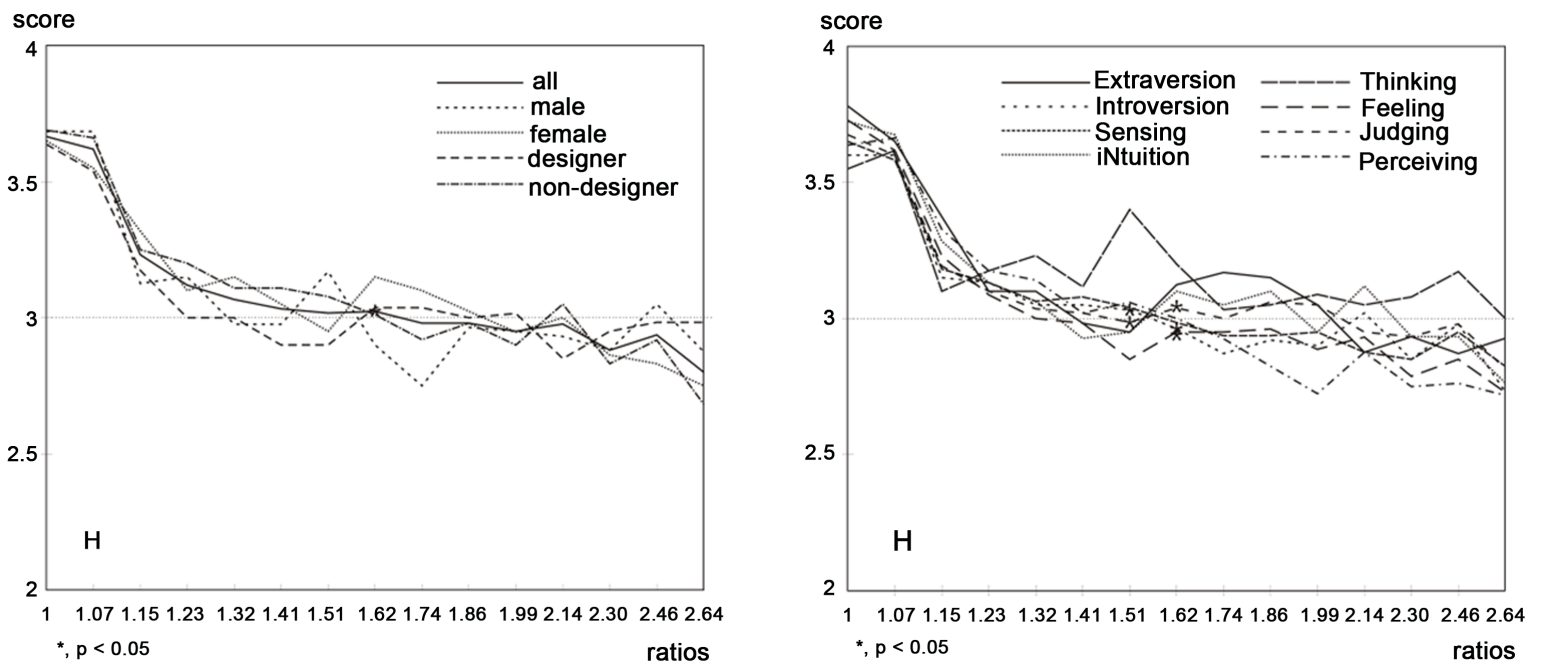

(a)
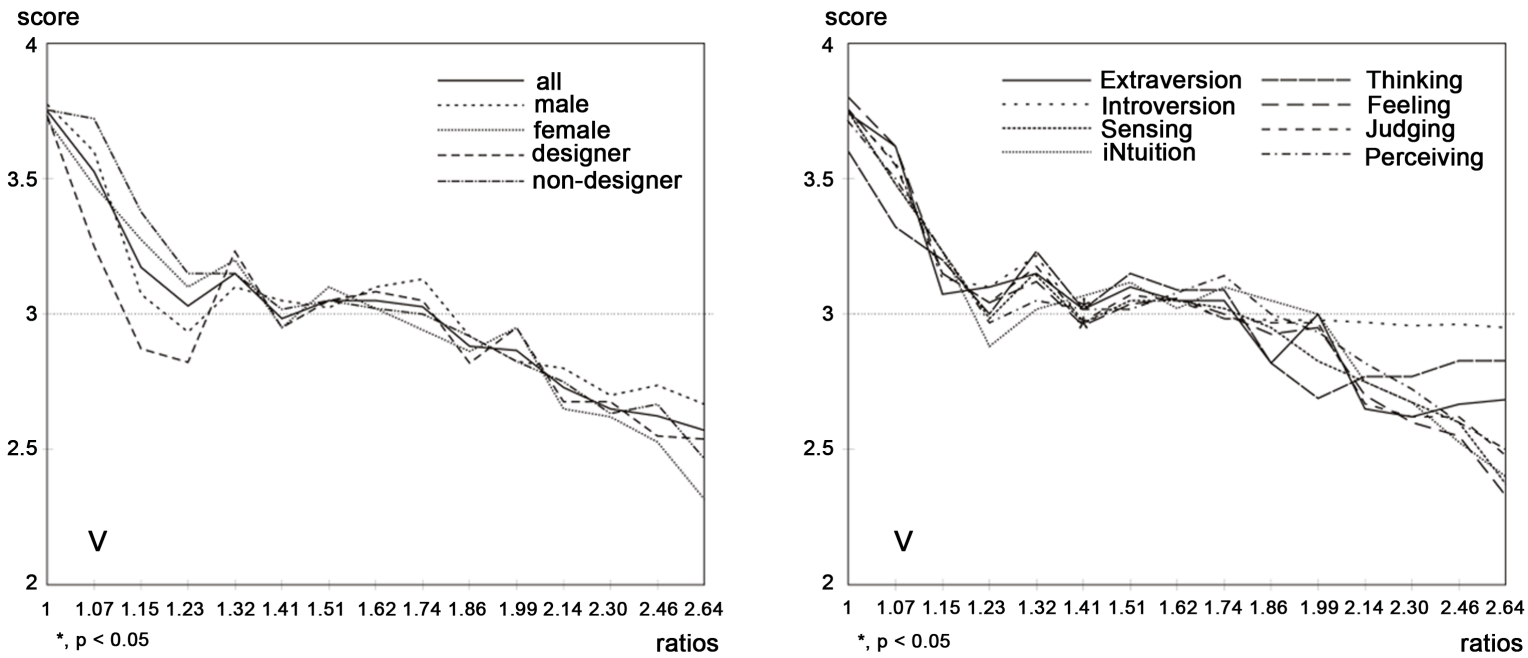

(b)

Figure 5. Assessment results: (a) Assessment result of $\mathrm{H}$ rectangles; (b) Assessment result of $\mathrm{V}$ rectangles.

One intriguing notice from the distribution of genders, we discover that $\mathrm{N}$ type female accounts as high as 3/4 of this percentage. Kroeger and Thuesen pointed out that only the percentage of S type and $\mathrm{N}$ was correlated with gender (Kroeger \& Thuesen, 1988). Approximately $2 / 3$ of the females belong to $N$ type.

From the overall result, we observe that when it comes to people choosing their favorite ratios, golden rectangles are usually the least favorite (degree of preference is average), while on the contrary the squares have been more widely chosen. This result slightly differs from the result of Fechner, in which the participants were inclined to like square, nonetheless golden rectangles still won over the regular square (Fechner, 1876). This could be discussed from the Berlyne's conservative inference (Berlyne, 1970), that when comparing square with rectangles, the Western people were inclined to show favor for rectangles while the Oriental people believe that squares are more stable visually. The result of the participants did not like extreme ratios, which clearly refuted (Godkewitsch, 1974).

Supposing people make distinction between personalities, some personalities consider golden ratios as the most aesthetics, while on the contrary some personalities dislike these ratios. For example, ESFP and ENFJ like golden ratios the most, but the ENFP will detest this point. Therefore, we know that different personalities will result in different ratios of preference. From the aforementioned literature, we either believe or query the concept of the existence of golden ratios. The study believes there is no absolute right or wrong to either concept, 
with the reason that neither takes into account the difference of individual personality. Additionally, the gender factor of the study is also one of the impacts, resulting in the significant difference in preference between male and female, whereas the female show far more preference over golden ratios than males.

\section{Conclusion}

The study applies MBTI psychology test to distinguish the 4 pairs of basic personalities and to conduct preference assessment on rectangle ratios. The result reveals that: 1) The study result differs significantly from the personality of American people, with the statistical result showing the majority of personalities fall on taking care type and civil servant type, while the general type and challenging type account for the least favorite; 2) The preference of ratios can be divided into three trends: great preference for the ratio of square, average degree of preference for golden ratios and a gradual declining dislike for ratios after golden ratios; 3 ) Personality will impact the ratio of preference. V6, $\mathrm{H} 7$ and $\mathrm{H} 8$ with different ratios have been preferred by different personalities. I type and $\mathrm{T}$ type personalities generally prefer $\mathrm{V} 6, \mathrm{~S}$ type and $\mathrm{J}$ type generally prefer $\mathrm{H} 7$, while $\mathrm{F}$ type and $\mathrm{J}$ type generally prefer the golden ratios H8; 4) Male and female with non-designer background will have different degrees of preference on golden ratios, whereas the female like the golden ratio while the male dislike it. Most people with designer background all show inclination towards golden ratios.

\section{References}

Benjafield, J. (1976). The "Golden Rectangle”: Some New Data. American Journal of Psychology, 89, 737-743. http://dx.doi.org/10.2307/1421471

Benjafield, J. (2011). Golden Section Relations in Interpersonal Judgement. British Journal of Psychology, 69, 25-35. http://dx.doi.org/10.1111/j.2044-8295.1978.tb01629.x

Benjafield, J., \& Adams-Webber, J. (2011). The Golden Section Hypothesis. British Journal of Psychology, 67, 11-15. http://dx.doi.org/10.1111/j.2044-8295.1976.tb01492.x

Berlyne, D. E. (1970). Aesthetics and Psychobiology. New York: Appleton-Centyry-Crofts Press.

Dolphin, C. (2009). Type Statistics and Surveys. http://en.wikipedia.org/wiki/Myers-Briggs Type Indicator\#cite note-24

Fechner, G. T. (1876). Vorschule der Aesthetik. Leipzing: Breitkopf and Härtel Press.

Godkewitsch, M. (1974). The Golden Section: An Artifact of Stimulus Rang and Measure of Preference. American Journal of Psychology, 87, 269-277. http://dx.doi.org/10.2307/1422021

Huang, W. H. (2008). A Study on the Color Preference and Personality Analysis of Extension Education Center Student in National Taiwan University of Art. Journal of Graphic Communication Arts, 97, 109-112.

Kroeger, O., \& Thuesen, J. M. (1988). Type Talk: The 16 Personality Types That Determine How We Live, Love, and Work. New York: Dell Press.

Lin, C. Y., \& Chuang, M. C. (2003). A Study on the Relationship between Color Preference and Personal Traits of College Students in Taiwan. Journal of Taiwan of Find Arts, 51, 34-43.

Mario, L. (2003). The Golden Ratio: The Story of Phi, the World's Most Astonishing Number. New York: Broadway Press.

McManus, I. C. (1980). The Aesthetics of Simple Figure. British Journal of Psychology, 71, 505-524. http://dx.doi.org/10.1111/j.2044-8295.1980.tb01763.x

Nienstedt, C. W., \& Ross, S. (1951). Preferences for Rectangular Proportions in College and the Aged. The Pedagogical Seminary and Journal of Genetic Psychology, 78, 153-158. http://dx.doi.org/10.1080/08856559.1951.10533573

Pittenger, D. J. (1993). Measuring the MBTI...And Coming Up Short. Journal of Career Planning and Placement, 54, 48-53.

Schiffman, H. R., \& Bobka, D. J. (1978). Preference in Linear Partitioning: The Golden Section Reexamined. Perception and Psychophysics, 24, 102-103. http://dx.doi.org/10.3758/BF03202979

Thompson, G. G. (1946). The Effect of Chronological Age on Aesthetic Preferences for Rectangles of Different Proportions. Journal of Experimental Psychology, 36, 50-58. http://dx.doi.org/10.1037/h0054675 